\title{
Microstructure and Mechanical Performance of Cu-Sn-Ti-Based Active Braze Alloy Containing In Situ Formed Nano-Sized TiC Particles
}

\author{
Christian Leinenbach, Robert Transchel, Klea Gorgievski, Friedrich Kuster, Hans Rudolf Elsener, and Konrad Wegener
}

\author{
(Submitted December 22, 2014; in revised form February 23, 2015; published online March 13, 2015)
}

\begin{abstract}
A Cu-Sn-Ti-based active brazing filler alloy was in situ reinforced with nanosized TiC particles by adding different amounts of a cellulose nitride-based binder. The TiC particles emanate from a reaction of the Ti within the filler alloy with the carbon from the binder that does not decompose completely during heating. The correlation between the microstructure and mechanical performance was studied. In addition, the effect of different binder amounts on the shear strength and cutting performance of brazed diamond grains was studied in shear tests and single grain cutting tests. The results clearly show that the mechanical performance of the brazed diamond grains can be improved by the formation of TiC particles. This is attributed to particle strengthening of the filler alloy matrix as well as to the decreasing grain size and more homogeneous distribution of the $(\mathrm{Cu}, \mathrm{Sn})_{3} \mathrm{Ti}_{5}$ phase with increasing amount of binder.
\end{abstract}

Keywords active brazing, composite, diamond, in situ reinforcement

\section{Introduction}

Active brazing of diamonds is one of the key technologies to manufacture single layer grinding and dressing tools. Brazing of diamonds requires active filler alloy systems, where the reactive element, such as titanium reacts with the diamond surface. This reaction results in the formation of a thin interfacial $\mathrm{TiC}$ reaction layer which is essential for the development of a strong joint between the diamond and the filler alloy (Ref 1). In general, $\mathrm{Cu}-\mathrm{Sn}$ and $\mathrm{Ag}-\mathrm{Cu}$ filler alloys are frequently used for diamond brazing. In comparison to electroplated diamond and dressing tools, the formation of a brazing fillet enables a larger protrusion length of the diamond, which increases the chip space. Due to these advantages, Burkhard et al. (Ref 2) developed a method that allows the predefined arrangement of abrasive particles by applying adhesive points onto the tool body, which further enlarges the chip space. Nowadays, such tools are commonly known as engineered grinding tools (EGT). Despite the improved bond-

Christian Leinenbach, Klea Gorgievski, and Hans Rudolf Elsener, Empa, Swiss Federal Laboratories for Material Science and Technology, Überlandstrasse 129, 8600 Dübendorf, Switzerland; Robert Transchel, Empa, Swiss Federal Laboratories for Material Science and Technology, Überlandstrasse 129, 8600 Dübendorf, Switzerland and Institute of Machine Tools and Manufacturing (IWF), ETH Zurich, Tannenstrasse 3, 8092 Zurich, Switzerland; Friedrich Kuster, Institute of Machine Tools and Manufacturing (IWF), ETH Zurich, Tannenstrasse 3, 8092 Zurich, Switzerland; and Konrad Wegener, Institute of Machine Tools and Manufacturing (IWF), ETH Zurich, Tannenstrasse 3, 8092 Zurich, Switzerland and inspire AG, ETH Zurich, Tannenstrasse 3, 8092 Zurich, Switzerland. Contact e-mail: Christian.Leinenbach@empa.ch. ing mechanism, active-brazed EGTs have shown an early failure due to grain pull-out, as stated by Pinto (Ref 3). In addition, the work pieces to be ground are often very hard, which leads to pronounced wear of the filler alloy. These findings caused additional systematic research concerning the bonding and failure mechanisms of brazed diamond steel joints. Buhl et al. (Ref 4) investigated the influence of the brazing parameters on the microstructure and phase composition as well as residual stress and the bond strength. They found that also with increasing brazing temperature and time and thus increasing thickness of the $\mathrm{TiC}$ reaction layer, the shear strength decreased significantly. In a further work, Buhl et al. (Ref 5) analysed the failure mechanisms of differently sized diamonds actively brazed with an Ag-Cu-based and $\mathrm{Cu}-\mathrm{Sn}$-based filler alloy in single grain tests. They found out that smaller diamonds mainly fail due to grain pull-out, whereas larger grains tend to fracture.

The performance of brazed diamond tools is therefore strongly depending on the properties of the active filler alloy. One possibility to improve the strength and abrasion resistance of a filler alloy is reinforcement with hard particles. In the case of active brazing, the reinforcement can be achieved by the addition of $\mathrm{SiC}, \mathrm{TiC}, \mathrm{WC}, \mathrm{W}$, or Mo particles, as mentioned by Shiue et al. (Ref 6). Qin et al. (Ref 7) used SiC particles to reinforce $\mathrm{Ag}-26.7 \mathrm{Cu}-4.6 \mathrm{Ti}$ (wt.\%) filler alloy for joining carbon-carbon $(\mathrm{C} / \mathrm{C})$ composites and prove the maximum shear strength applying 15 vol.\% SiC. Zhu and Chung (Ref 8) added metal-coated carbon fibers to an active filler alloy and observed an increase of the shear strength from 18 to $28 \%$. Suedmeyer et al. (Ref 9) reinforced SnAgTi-alloys using W particles and observed a maximum of the shear strength at a $\mathrm{W}$-content of $5 \mathrm{wt} . \%$. Usually, the particles are added to the filler alloy powder followed by extensive mechanical mixing, e.g., ball milling. Another method is controlled in situ formation of carbides during the brazing process. Elsener et al. showed that this can be achieved by the reaction of $\mathrm{C}$ from excess binder and titanium which leads to the formation of nano-sized titanium-carbide particles in a $\mathrm{Cu}-\mathrm{Sn}$-Ti-based filler 
alloy (Ref 10). This technique avoids the time-consuming mixing step in order to achieve a homogenous distribution of brazing powder and nano-sized particles, which is further complicated by increased agglomeration effects. In their work, Elsener et al. verified the formation of $\mathrm{TiC}$ in the microstructure by TEM and measured an improved erosion resistance of the TiC reinforced filler during sand blasting tests, which was assumed to be due to a refined microstructure of the filler alloy. However, no results on the mechanical performance of the TiC reinforced filler or on the feasibility of this approach for obtaining diamond-steel joints have been presented so far. The present paper provides an experimental study on the correlation between microstructure and hardness of reinforced $\mathrm{Cu}-\mathrm{Sn}$ filler alloys with in situ formed $\mathrm{TiC}$ particles as a function of the binder content. It also reveals its effect on mechanical performance of brazed diamond-steel joints in shear and single grain cutting tests.

\section{Materials and Methods}

\subsection{Filler Alloy and Joint Preparation}

The applied $\mathrm{Cu}-\mathrm{Sn}$-based filler alloy had a composition of $73.9 \mathrm{Cu}, 14.4 \mathrm{Sn}, 10.2 \mathrm{Ti}$, and $1.5 \mathrm{Zr}$ (wt.\%) with a liquidus temperature of $1198 \mathrm{~K}$ and a solidus temperature of $1141 \mathrm{~K}$. The filler metal powder with an average particle size of $12 \mu \mathrm{m}$ was processed to a paste using a cellulose nitride $(\mathrm{CN})$ binder with a nitrogen content of $12.3 \mathrm{wt} . \%$. The paste consisted of 6.5 wt.\% CN (incl. 35 wt.\% iso-propanol) dissolved in $99+\%$ octyl acetate. The thermal degradation of $\mathrm{CN}$ starts with denitration at $480 \mathrm{~K}$ followed by the pyrolysis at $486 \mathrm{~K}$ with a char yield of $5.3 \mathrm{wt} \%$ (Ref 10). The selected binder contents in the brazing paste were $0.4,1,3$, and 5 wt. $\%$. A binder content of $0.4 \mathrm{wt} . \%$ leads to a microstructure consisting of a $(\mathrm{Cu}, \mathrm{Sn})$ solid solution matrix with an intermetallic $(\mathrm{Cu}, \mathrm{Sn})_{3} \mathrm{Ti}_{5}$-phase. This reference state was already described by Buhl (Ref 4). In contrast, higher binder contents such as 1,3 , and 5 wt. $\%$ lead to increasing amounts of residual $\mathrm{C}$ which can react with $\mathrm{TiC}$ during heating. Table 1 shows the calculated carbon content (added as CN) in the preforms with respect to the amount of filler metal for the different samples.

The brazing pastes were applied on pure Mo plates $(\varnothing 20 \mathrm{~mm} \times 0.3 \mathrm{~mm}$, cf. Fig. 1a) which were placed in the evacuated chamber of a high vacuum furnace and heated up to $1203 \mathrm{~K}$ with a heating rate of $10 \mathrm{~K} / \mathrm{min}$. After a second heating phase at $20 \mathrm{~K} / \mathrm{min}$ up to $1203 \mathrm{~K}$, the filler alloy was molten and kept at this temperature for $10 \mathrm{~min}$, followed by cooling at a rate of $10 \mathrm{~K} / \mathrm{min}$. The cooling process was supported by argon flushing below a temperature of $573 \mathrm{~K}$. Mo was selected

Table 1 Carbon content (added as $\mathrm{CN}$ ) in preforms with respect to the amount of filler metal (Cu-14Sn-10Ti-1.5Zr, wt. \%)

\begin{tabular}{ccc}
\hline $\begin{array}{l}\text { Binder addition, } \\
\text { CN, wt.\% of solids content }\end{array}$ & $\begin{array}{l}\text { Carbon from } \\
\text { binder, at.\% }\end{array}$ & $\begin{array}{c}\text { Ratio Ti/C, } \\
\text { at.\%/at.\% }\end{array}$ \\
\hline 0.4 & 0.62 & 21.1 \\
1 & 1.49 & 8.9 \\
3 & 4.05 & 2.9 \\
5 & 6.61 & 2.0 \\
\hline
\end{tabular}

because it does not react with the filler alloy. These samples were used for a preliminary study of the microstructure brazed diamond-steel samples for shear tests were produced by brazing $1 \times 1 \times 0.5 \mathrm{~mm}^{3}$ single crystal diamond blocks (Monodite, ElementSix) onto X2CrNiMo18-14-3 (SS316L) austenitic steel blocks with the dimensions $30 \times 10 \times 5 \mathrm{~mm}^{3}$, as shown in Fig. 1(b). Prior to the brazing process, both substrates underwent a cleaning procedure (ultrasonic-assisted acetone rinsing) to remove all contaminations followed by a degassing in a high vacuum furnace for $45 \mathrm{~min}$ at $1073 \mathrm{~K}$.

In order to characterize the mechanical performance under operating conditions, a set of active-brazed single diamond pins shown in Figure 2(a) and (b) was produced with the identical material as the specimens for the shear tests. Hexa-octahedralshaped diamonds with a grit size of D851 (MBS 970 by Diamond Innovations) were positioned and adhered on the pin's front surface and subsequently active-brazed so that a squared plane of the hexa-octahedral diamond is orthogonal to the pin's axis and in the single grain cutting tests is acting as the flank face.

\subsection{Filler Alloy and Joint Characterization}

Thermal analysis was done in order to record the decomposition profile of the used CN-binder. The samples were characterized by thermogravimetry (TG). The measurements took place in an inert He atmosphere using a Netzsch STA 409 CD. A thermo-balance monitored the weight change of the samples during heating from 313 to $1203 \mathrm{~K}$ at a rate of $10 \mathrm{~K} /$ min under a $30 \mathrm{~mL} / \mathrm{min}$ helium gas flow. The pastes with

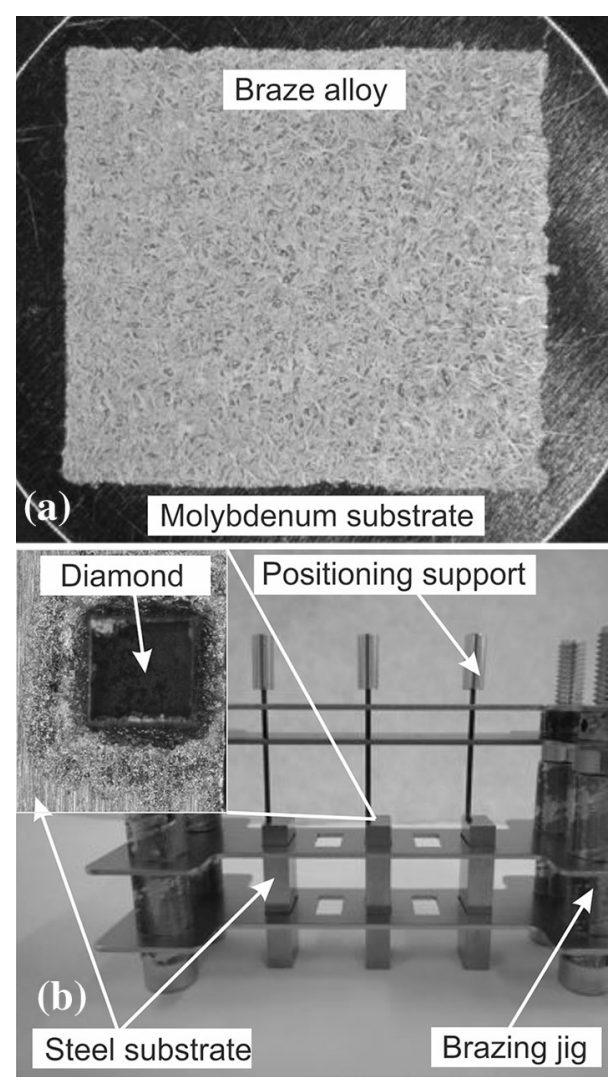

Fig. 1 (a) Molten and solidified filler alloy on a molybdenum specimen (b) brazing jig for active brazing of Monodite diamonds on steel substrates 


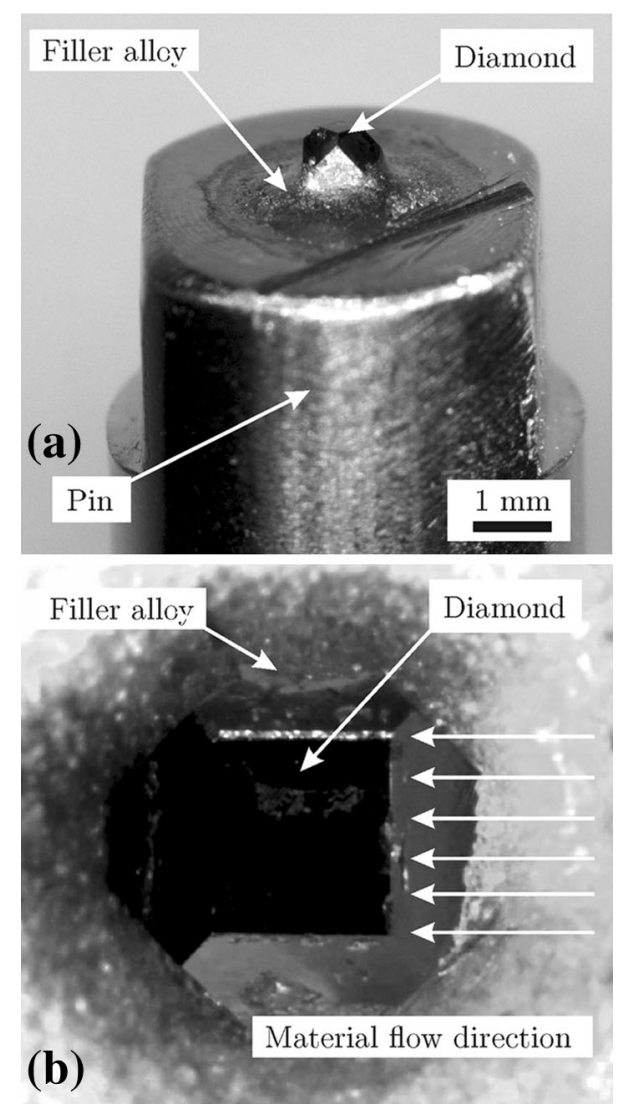

Fig. 2 (a) Pin with an active brazed single diamond (b) squared flank face of an active brazed single diamond

different binder contents were additionally characterized by differential scanning calorimetry (DSC) using a Netzsch DSC $404 \mathrm{C}$ Pegasus at a rate of $10 \mathrm{~K} / \mathrm{min}$ under a $70 \mathrm{~mL} / \mathrm{min}$ argon flow. Aluminium oxide crucibles were used for all tests.

The Mo substrates with the filler alloys were cut and embedded in a standard mounting resin. Afterwards, they underwent a standard metallographic preparation procedure starting with grinding (P2000) followed by polishing with a diamond suspension (grit size $1 \mu \mathrm{m}$ ). Scanning electron microscope (SEM) images were taken using the backscattered electron detector (BSE). This enables to detect and optically highlight different phases as well as the TiC particles in the microstructure. However, this method only allowed a qualitative identification of present phases. The software ImageJ was used for a quantification of the overall ratio of $\mathrm{TiC}$ particles for each binder content. For this reason, selected SEM micrographs of the samples with different binder contents were carefully analyzed. Associated histograms provide information about the colour distribution of the analysed image. The resulting histogram represents the three existing phases $(\mathrm{Cu}, \mathrm{Sn})$-matrix, $(\mathrm{Cu}, \mathrm{Sn})_{3} \mathrm{Ti}_{5}$-phase and $\mathrm{TiC}$ particles. Due to the weak intensity of the TiC particle peak, the threshold was set accordingly so that only the $\mathrm{TiC}$ particles became visible within the resulting image and the other phases were filtered out. The binary blackand-white images were carefully compared with the original SEM micrograph in order to avoid the quantification of artefacts like scratches. This method was applied to three different micrographs for each binder content with the purpose to quantify a value in order to objectively characterize the amount of particles and correlate to the different binder contents.

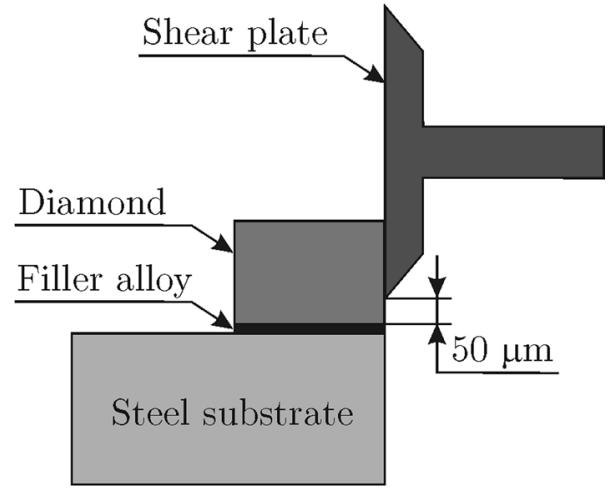

Fig. 3 Experimental setup for the shear tests (schematic)

For a more precise characterization of the filler alloy nanostructure, transmission electron microscopy (TEM) was applied. TEM samples were prepared by focused ion beam milling as described in (Ref 10,11). TEM investigations were performed with a Philips CM30 operated at 200-250 kV. Elemental maps were acquired by energy dispersive $\mathrm{x}$-ray analysis (EDX) in TEM using EDAX DX-4 microanalyzer.

The brazed diamond-steel specimens were metallographically prepared as described by Buhl et al (Ref 4) and subsequently characterized by SEM.

\subsection{Characterization of the Mechanical Performance of the Filler Alloy and Brazed Diamond-Steel Joints}

The Vickers hardness of the microstructure was determined using a Fischerscope HM 2000 microindenter. For this study, a test load of $80 \mathrm{mN}$ and a dwell time of $20 \mathrm{~s}$ were selected. Five measurements were averaged and the according standard deviations were determined. To measure the bond strength shear tests were carried out with the brazed diamond-steel samples. The experimental setup is schematically displayed in Fig. 3. A shear plate was displaced with a shear rate of $0.1 \mathrm{~mm} /$ $\mathrm{s}$ until the diamond steel joint eventually failed.

Single grain cutting experiments were conducted in order to analyse the mechanical performance of $\mathrm{Cu}-\mathrm{Sn}$-based active filler alloys containing in situ formed nano-sized TiC particles. Therefore, the single diamond pins were screwed into a radial bore hole of a cylindrical tool body so that the grain performs a circular path through the material, as displayed in Fig. 4(a). This single grain cutting tool was attached to the spindle of the test machine Willemin 518 MT. A specially designed MicroDyn dynamometer was attached to the test machine, as it has been already described in (Ref 5, 11). A multi charge amplifier (Kistler type: $5080 \mathrm{~A}$ ) was used to amplify the force signals that were sampled with a DAQ measuring board (NI 9222) using a sampling rate of $151.1 \mathrm{kHz}$, which allows a high resolution of such signals which is necessary because of their high frequency character. The low pass filter was set at a cut-off frequency of $6 \mathrm{kHz}$. As a work piece, a hardened $100 \mathrm{Cr} 6$ steel plate with a lapped surface and dimensions of $15 \times 15 \times 5 \mathrm{~mm}^{3}$ with a hardness of HRC61 was used. Diamond and carbon steel does not represent an industrially applied tool-work piece combination. However, it enables excellent qualities to analyse the material removal and failure mechanism of such diamonds. By applying an axial and radial feed, several scratches were placed parallel on the work piece surface with different cutting depths as exemplarily shown in Fig. 4(b). Thus, the radial 

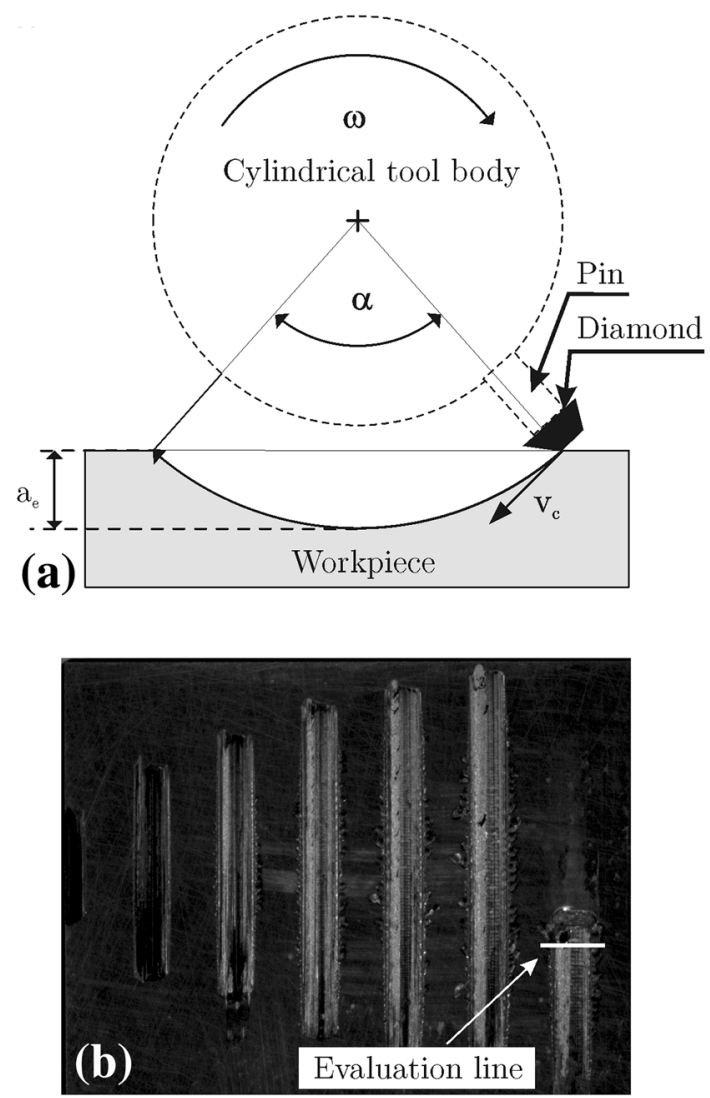

Fig. 4 Experimental setup of the single grain cutting tests (a) schematic of the contact kinematics (b) Single grain scratches

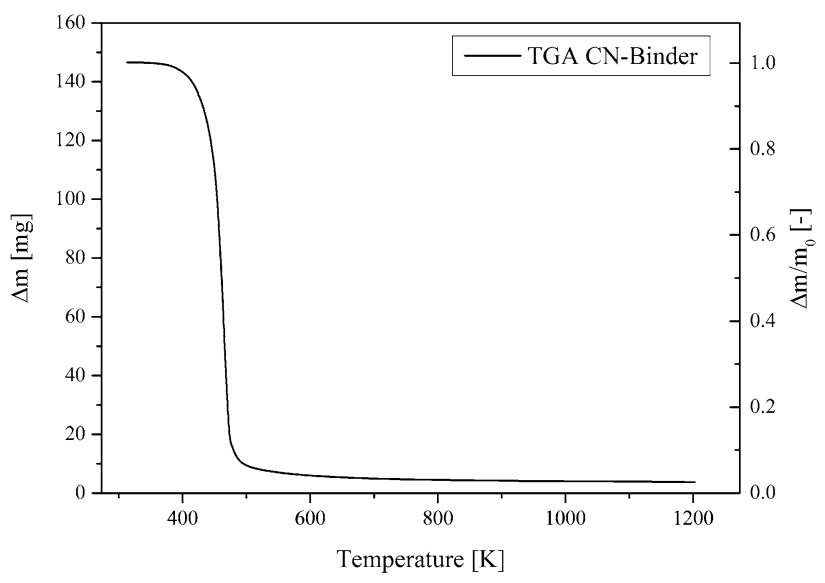

Fig. 5 TGA curve showing the mass change during heating due to the decomposition of the $\mathrm{CN}$ binder

cutting depth was continuously increased in order to force failure of the diamond bonding system. The tests were carried without any cooling lubricant. Because a pronounced effect of the grain orientation and the clearance angle on the resulting cutting forces was previously observed [cf. (Ref 11-13)], only grains with explicitly positive clearance angles and for which the edge of the diamond functioning as cutting edge was positioned perpendicular to the material flow direction as shown in Fig. 2(b) were selected.

An Alicona 3D infinite focus microscope was used to measure the three dimensional topography of the generated scratches. Using the corresponding analysis software, an evaluation has been fitted to quantify the cross section of the scratch orthogonally to the cutting direction prior to the point of failure. The associated cutting depths and scratch area $A_{c u}$ were calculated based on the contact time of the process force signal and correlated to the measured cutting forces with the purpose to calculate the specific cutting forces which is defined as follow:

$k_{\mathrm{c}}=\frac{F_{\mathrm{c}}}{A_{\mathrm{cu}}}$.

In addition, the ratio between the cutting force, $F_{\mathrm{c}}$, and the normal force, $F_{\mathrm{N}}$, was calculated according to

$\mu=\frac{F_{\mathrm{c}}}{F_{\mathrm{N}}}$.

\section{Results and Discussion}

\subsection{Thermal Behaviour and Microstructure Analysis}

The thermal decomposition profile of the binder is shown in Fig. 5. The TG curve of the $\mathrm{CN}$ binder shows that mass loss starts at around $373 \mathrm{~K}$ and that the binder mass decreased to $10 \%$ at $473 \mathrm{~K}$. It can be also seen that a small amount of $2-3 \%$ remains until high temperatures. Figure 6 shows the DSC curves of three pastes with different binder contents. All three curves exhibit an exothermic peak at around $473 \mathrm{~K}$, which corresponds to the pyrolysis of the binder. As can be expected, the peak becomes more pronounced with increasing binder content. The clearly marked endothermic peak just below $1173 \mathrm{~K}$ indicates the melting start of the alloy. The end of the alloy melting gives rise to a second smaller peak at the end of the melting range. At $673 \mathrm{~K}$, the DSC signal shows a continuous decrease toward the endothermic direction. This decrease accelerates between approximately 873 and $1073 \mathrm{~K}$ and becomes more pronounced with increasing binder amount. This signal change is probably caused by an overall endothermic reaction of the $\mathrm{Ti}$ in the filler alloy with the binder residuals. This reaction obviously starts already in the solid state, far below filler alloy melting.

The micrograph of the reference filler alloy on the Mo substrate with $0.4 \mathrm{wt} \% \mathrm{CN}$ binder content displayed in Fig. 7(a) clearly shows the $\mathrm{Cu}-\mathrm{Sn}$-matrix and the $(\mathrm{Cu}, \mathrm{Sn})_{3}$ $\mathrm{Ti}_{5}$-phases. TiC particles are evidently not present in the analysed microstructures, as it was already observed by Buhl et al. (Ref 4, 5). Increased binder contents are simultaneously accompanied by higher solvent contents. This causes a lower viscosity of the brazing pastes and leads thereby to a decreased filler alloy thickness. Corresponding SEM micrographs displayed in Fig. 7(b and d) show this effect and additionally outline a progressive appearance of black nano-sized dots that were identified as TiC particles by additional XRD measurements. The measured TiC fractions according to the image analysis are shown in Table 2. A clear increase of the amount of $\mathrm{TiC}$ with increasing binder content can be seen.

Figure 8 reveals the fine scale particles dispersed in both $\mathrm{Cu}$ - rich and intermetallic phases in the alloy with $3 \mathrm{wt} . \%$ binder. They can be clearly seen in the brightfield (BF, Fig. 8a) and in the darkfield (DF) image with $g=[202]$ TiC (Fig. 8b). The particles were identified by the selected area diffraction 
analysis as TiC (cf. insert in Fig. 8a). Figure 8(c) shows the STEMx ray map for $\mathrm{Cu}, \mathrm{Ti}, \mathrm{Sn}$, and $\mathrm{C}$ in which the occurrence of $\mathrm{TiC}$ particles can be also seen. The distribution of these particles was manly restricted to grain boundaries and microporosity in the sample. The size of the particles ranged between 10 and $80 \mathrm{~nm}$ and they have cuboidal to round morphologies. However, larger TiC particles of up to $250 \mathrm{~nm}$ could be occasionally observed. The observations are generally consistent with the results of Elsener et al. (Ref 10) who measured an average particle size of $30 \mathrm{~nm}$.

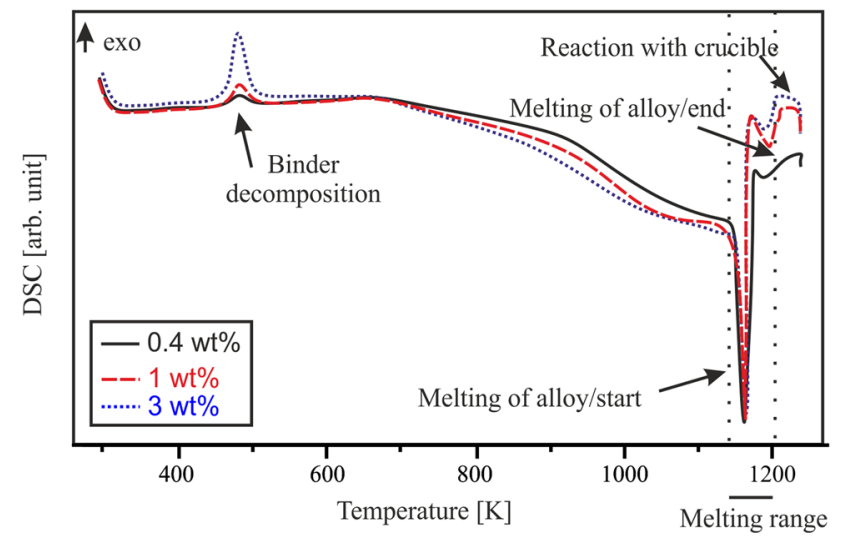

Fig. 6 DSC curves of three filler alloy pastes containing different amounts of binder
Both the SEM and TEM images suggest that the TiC particles are inhomogeneously distributed in the filler alloy matrix (cf. e.g., Fig. 7c). It was observed that they preferentially form cell structures whose size correspond to the size of the brazing powder grains, as similarly observed in (Ref 10). This indicates that the TiC particle formation is initiated already in the solid state near the surface of the initial brazing powder grains, which is consistent with the above mentioned DSC measurements. Obviously, no pronounced convection occurs in the liquid filler so that the $\mathrm{TiC}$ particles remain more or less at the place where they have formed The fraction of the $(\mathrm{Cu}, \mathrm{Sn})_{3} \mathrm{Ti}_{5}$ phase (approx. 28 vol.\%) did not change with increasing content of binder. However, the average grain size decreased significantly. Since the $(\mathrm{Cu}, \mathrm{Sn})_{3} \mathrm{Ti}_{5}$ grains where rather elongated in the reference alloy with $0.4 \mathrm{wt} . \%$ binder and round shaped in the alloy with 3 wt.\% binder, they are difficult to compare by their size. Therefore, the average grain cross section on the SEM images was used instead. It was $21.6 \mu \mathrm{m}^{2}$ in the reference alloy with $0.4 \mathrm{wt} . \%$ binder and $7.2 \mu \mathrm{m}^{2}$ in the $3 \mathrm{wt} \%$ binder alloy. The reason for the grain refinement is that

Table 2 TiC content determined by image analysis

\begin{tabular}{cc}
\hline Binder content, wt. \% & TiC, vol.\% \\
\hline 0.4 & 0 \\
1 & $0.55 \pm 0.21$ \\
3 & $2.07 \pm 0.81$ \\
5 & $7.50 \pm 3.1$ \\
\hline
\end{tabular}

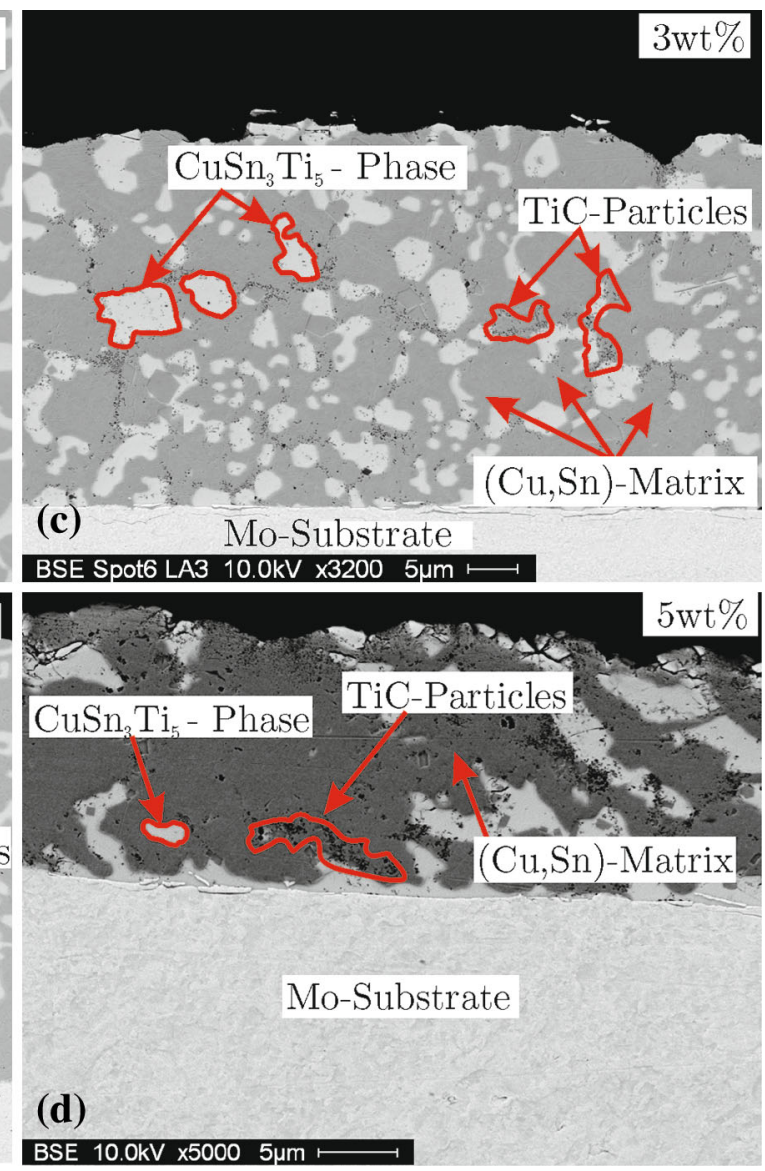

Fig. 7 SEM-micrograph of the filler alloy with (a) 0.1 wt.\%, (b) 1 wt.\%, (c) 3 wt.\% and (d) 5 wt.\% CN binder content 

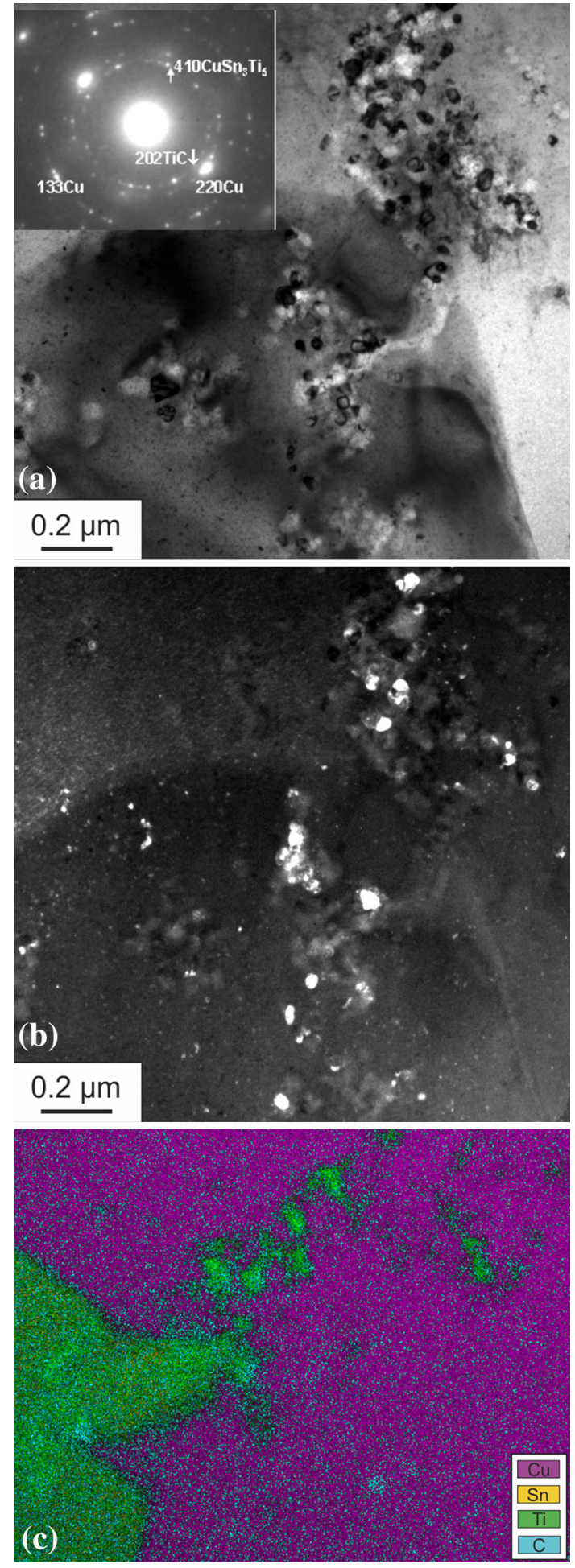

Fig. 8 TEM - Microstructure of the alloy with 3 wt.\% binder (a) $\mathrm{BF}$ and SADP, (b) DF $\mathrm{g}=[202] \mathrm{TiC}$, (c) STEM x ray map

TiC particles form many heterogeneous nucleation sites for the formation of $(\mathrm{Cu}, \mathrm{Sn})_{3} \mathrm{Ti}_{5}$ upon solidification of the braze alloy due to local Ti enrichment in the melt.

Binder contents of $5 \mathrm{wt} . \%$ lead to a strong liquefaction of the associated brazing pastes due to high amount of the included solvent. Such liquefied brazing pastes are difficult to handle properly, show a poor bonding strength to the

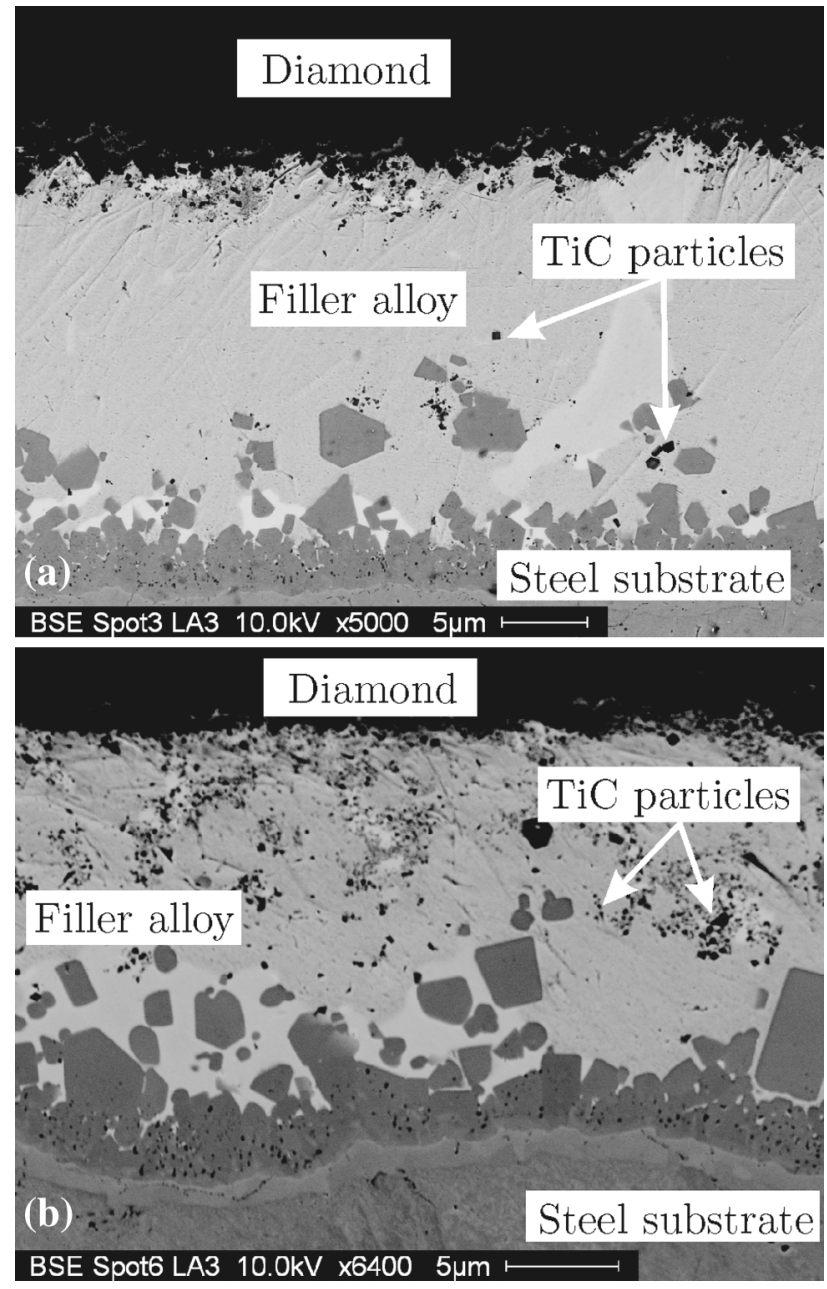

Fig. 9 Overview of the brazing gap of a diamond-steel joint produced with a brazing paste containing (a) $1 \mathrm{wt} . \% \mathrm{CN}$ binder and (b) 3 wt.\% $\mathrm{CN}$ binder

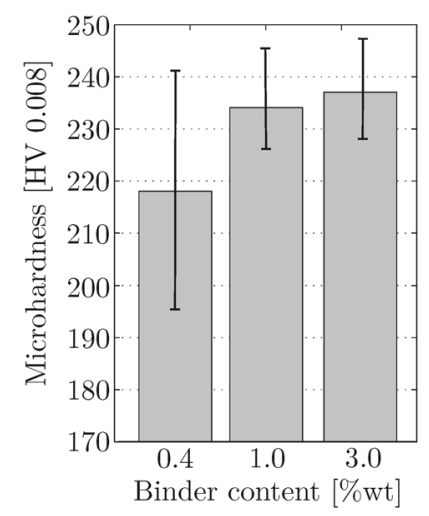

Fig. 10 Microhardness (HV) of the reinforced $(\mathrm{Cu}, \mathrm{Sn})$ matrix

molybdenum substrate or cause a strongly varying braze layer thickness. Furthermore, filler alloy layers tend to be prone to porosity and micro-cracks that lead to spallation of the braze layer. Therefore, the specimens with this particular binder content were not selected for any subsequent laboratory tests to determine the resistance toward mechanical loadings. 
Table 3 Shear strength of samples produced with different binder contents

\begin{tabular}{|c|c|c|c|c|}
\hline Binder content, wt. $\%$ & Sample Nr. & Shear strength, MPa & Average strength, MPa & Failure mode \\
\hline \multirow[t]{3}{*}{0.4} & 1 & 188 & $199 \pm 18$ & Diamond fracture \\
\hline & 2 & 220 & & Diamond fracture \\
\hline & 3 & 189 & & Diamond fracture \\
\hline \multirow[t]{3}{*}{1} & 1 & 223 & $230 \pm 89$ & Diamond fracture \\
\hline & 2 & 323 & & Diamond fracture \\
\hline & 3 & 145 & & Diamond fracture \\
\hline \multirow[t]{3}{*}{3} & 1 & 188 & $285 \pm 158$ & Diamond fracture \\
\hline & 2 & 205 & & Diamond fracture \\
\hline & 3 & 471 & & Bond shear failure \\
\hline
\end{tabular}

Cross-sections of the diamond-steel joints produced with braze alloys containing 1 and 3 wt.\% $\mathrm{CN}$ binder were produced for microstructural analysis. Figure 9 shows representative BSE images of the whole brazing gap in samples produced with 1 wt. \% $\mathrm{CN}$ and 3 wt.\% CN, respectively. These pictures show that different phases have developed during the brazing process. The amount of $\mathrm{TiC}$ appears to be lower than in the Mo substrate samples. On the steel substrate side a pronounced layer of the $(\mathrm{Fe}, \mathrm{Ni})_{2} \mathrm{Ti}$ Laves-phase has formed, as has been reported by Buhl et al. (Ref 4). In addition, it is well known that a certain amount of $\mathrm{Ti}$ is also consumed by the formation of a $\mathrm{TiC}$ reaction layer on the diamond side. This leads to a reduction of the $\mathrm{Ti}$ in the liquid filler and consequently to a lower amount of the $(\mathrm{Cu}, \mathrm{Sn})_{3} \mathrm{Ti}_{5}$ phase as well as of the $\mathrm{TiC}$ particles in the filler alloy matrix in comparison with the samples with Mo substrates.

\subsection{Hardness and Shear Performance of Diamond-Steel Joints}

Due to the multiple phases in the microstructure, the hardness measurement only allows a quantitative evaluation of the entire filler alloy system as an averaged hardness. Therefore, the indenter was positioned so that all existing phases are involved in the measuring cycle. The averaged results are shown in Fig. 10.

It can be clearly seen that an increasing binder content leads to an increase of the average hardness. The reference filler alloy shows a hardness of HV $(218 \pm 21)$. A binder content of 1 wt.\% causes a hardness increase of $7.3 \%$ up to $\mathrm{HV}$ $(234 \pm 10)$ and a 3 wt.\% binder content increases the hardness by $8.7 \%$ up to HV $(237 \pm 9)$. However, the standard deviations are comparably high resulting from the inhomogeneous distribution of the involved phases in the indentation area. A subsequent SEM investigation revealed that some indents were positioned in areas containing many $\mathrm{TiC}$ particles whereas others in areas almost free of TiC. Nevertheless, it can be assumed that the increase of the microhardness is related to the increasing amount of $\mathrm{TiC}$ particles as well as the increasing number of smaller grains of the hard $(\mathrm{Cu}, \mathrm{Sn})_{3} \mathrm{Ti}_{5}$ in the $(\mathrm{Cu}, \mathrm{Sn})$ matrix.

Shear tests were carried out in order to characterise the bond strength of the diamond-steel joints in shear loading mode by implying a shear force through a shear plate. With this setup, the diamond-steel joint is shear loaded until a bond failure or a fracture of the active-brazed diamond occurs. Due to the brittle material properties, diamonds tend to fracture in this specific experimental setup, as shown in Table 3. This behaviour was previously observed by Buhl et al. (Ref 4) and is probably related to a not ideal alignment of the shear tool relative to the diamond because of floating and elastic deformation of the device. This leads to localized forces, resulting in locally very high compressive stresses that may exceed the fracture strength of the diamond. It can be assumed that the relatively large diamond blocks contain more defects in comparison with smaller diamond grains, leading to a decrease of the macroscopic diamond strength. Therefore, the measured data can be considered as values for the fracture strength of the diamonds rather than the actual shear strength of the associated joints. However, they can be considered as a lower limit value for the resistivity of the diamond-steel joints against shear load, and it can therefore be concluded that the actual bond shear strength is higher than the measured values. The individual shear test values of the three different test series are similar and reach values of up to $323 \mathrm{MPa}$. In one case of $3 \mathrm{wt} . \%$ binder content, a maximum shear strength of $471 \mathrm{MPa}$ without diamond fracture was achieved, which is thus the true strength of the bond. Comparing this value to previous shear strength data of diamond-steel joints with non-reinforced filler alloy and varying brazing parameters as presented in (Ref 5) indicates a significant increase of the resulting shear strength, which again can be considered as a result of the formation of $\mathrm{TiC}$ particles, but also of the formation of smaller $(\mathrm{Cu}, \mathrm{Sn})_{3} \mathrm{Ti}_{5}$ grains as already mentioned above. However, it is clear that this statement is weak since it is based on a single test value, and more tests with an improved test setup would be required.

\subsection{Failure Behaviour of Diamond-Steel Braze Joints in Single Grain Cutting Tests}

The tests described in section 3.2 provide basic data regarding the mechanical performance of particle-reinforced filler alloys and their associated diamond joints. Since the applied loading states, for instance the uniaxial load on the diamond-steel joint by the shear plate does not correspond to the triaxial load state occurring as a result of the grain-material interaction during grinding, a more application-oriented approach is required in order to determine the applicability of TiC reinforced filler alloys for grinding tools. For this reason, single grain cutting operations were performed with the purpose to induce failure of the brazed diamond so that the bond strength under grinding wheel conditions can be evaluated.

The SEM images in Fig. 11 show typical failure mechanisms that occurred for the different samples. The reference filler alloy with the binder content of 0.4 wt. $\%$ showed grain pullout, which is displayed in Fig. 11(a), and which was already reported by Buhl et al. (Ref 5). The grains brazed with the filler alloy with $1 \mathrm{wt} . \%$ binder content showed neither fracture nor 
pull-out of the diamond during these experiments, as shown in Fig. 11(b). No obvious differences in the joint appearance could be detected between the samples brazed with 0.4 and 1 wt.\% binder, and brazing fillets around the diamonds could be observed in both cases. However, the brazing fillet has partially been removed on the side of the incoming material flow during the test. Despite the fact of the increased hardness and shear strength, the grains embedded in a filler alloy with 3 wt. $\%$ binder content are characterized by an early grain
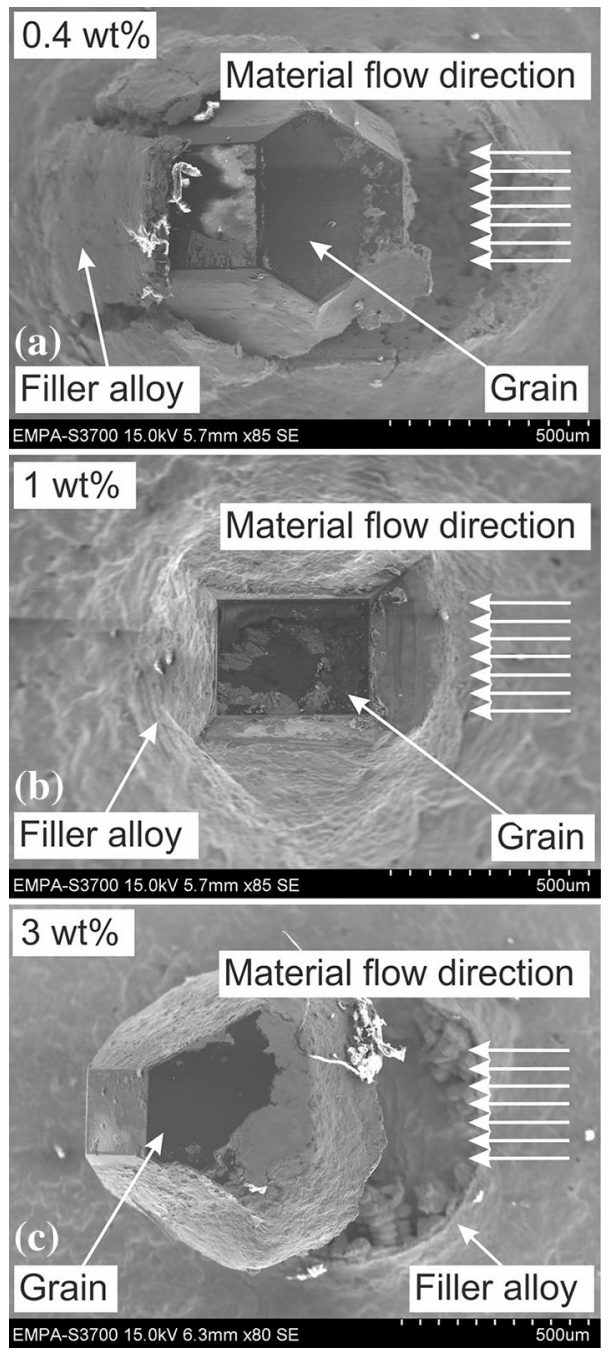

Fig. 11 Grains brazed with (a) 0.4 wt.\%, (b) 1 wt.\% and (c) 3 wt.\% binder after the single grain cutting test pull- at very low process forces, as displayed in Fig. 11(c). The rather liquid brazing paste apparently leads to an insufficient formation of a cone around the prepositioned diamond.

Table 4 summarizes the observed failure modes of applied diamonds with the corresponding cutting force $F_{c}$, the normal force $F_{N}$ as well as the cutting force ratio, $\mu$, at failure. In some

(a)
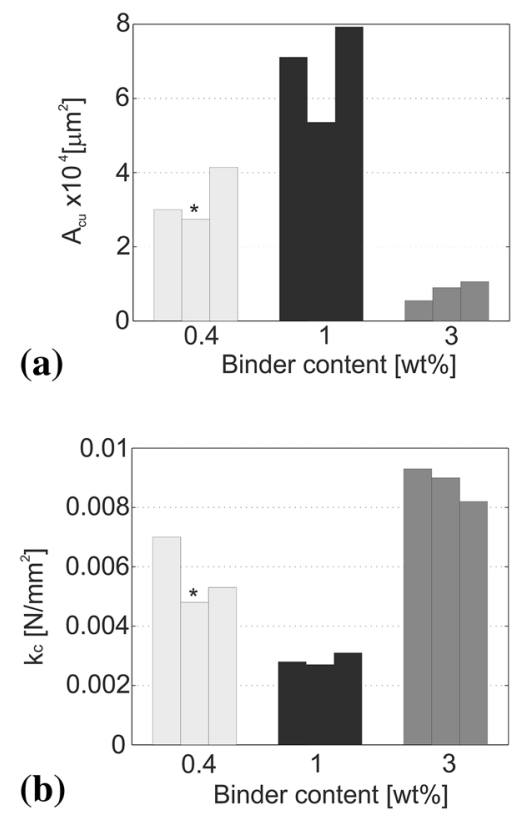

Fig. $12 F_{\mathrm{c}} / A_{\mathrm{cu}}$-ratios (a) and the cross-section area $A_{\mathrm{cu}}$ (b) at the moment of failure

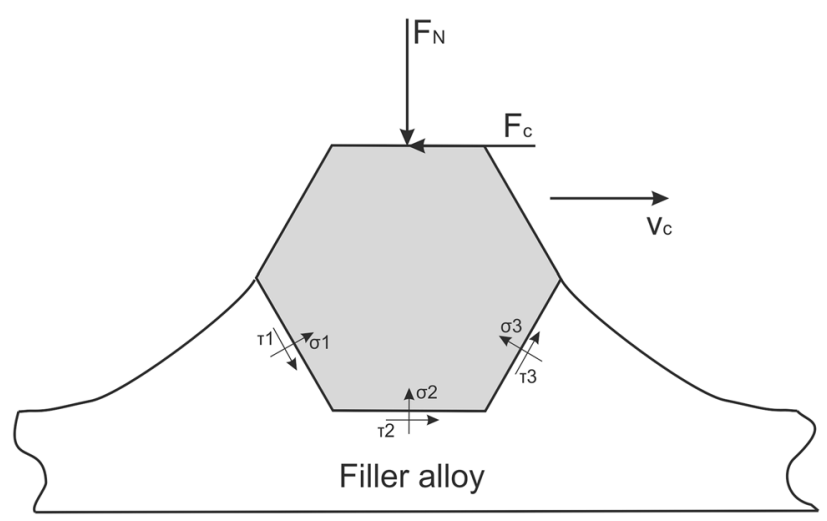

Fig. 13 Loads on diamond grain during single grain cutting test

Table 4 Failure modes of the single grains embedded in particle reinforced filler alloy

\begin{tabular}{cccccc}
\hline Binder content, wt.\% & Sample Nr. & $\boldsymbol{F}_{\mathbf{c}}, \mathbf{N}$ & $\boldsymbol{F}_{\mathbf{N}}, \mathbf{N}$ & $\boldsymbol{\mu},-$ & Failure mode \\
\hline \multirow{2}{*}{0.4} & 1 & 209.63 & 298.43 & 0.70 & No failure \\
& 2 & 130.80 & 191.69 & 0.68 & Grain fracture \\
\multirow{2}{*}{1} & 3 & 218.24 & 304.76 & 0.72 & Grain pullout \\
& 1 & 201.58 & 314.00 & 0.63 & No failure \\
3 & 2 & 143.42 & 226.31 & 0.63 & No failure \\
& 3 & 245.84 & 388.07 & 99.65 & Grain pullout \\
& 1 & 50.92 & 156.27 & 0.52 & Grain pullout \\
& 2 & 80.67 & 180.82 & Grain pullout \\
\hline
\end{tabular}


cases, no diamond failure could be induced up to the maximum force that can be applied on the dynamometer and the process force measured for the highest cutting depth is displayed. A further increase of the cutting depth would have led to dynamometer damage. In Fig. 12, the specific cutting forces $k_{\mathrm{c}}$ at failure or of the scratches with the highest cutting depth as well as the measured cross sectional areas $A_{\mathrm{cu}}$ of the scratches are shown. These values can be considered as a measure for the efficiency of the material removal process and thus indirectly as a measure for the joint quality. The tests with the grains brazed with brazing filler with 1 wt.\% binder revealed significantly increased values of $A_{\mathrm{cu}}$ and lower $F_{\mathrm{c}} / A_{\mathrm{cu}}$ ratios in comparison with the reference filler alloy with 0.4 wt.\% binder. Since all selected diamond grains had almost the same size and assuming the same diamond embedding after brazing in the two cases, the failure model proposed by Buhl et al. (Ref 5) can be used to compare the joint qualities. According to this model, which is sketched in Fig. 13, failure occurs due to grain pull out if the shear stress in the diamond-filler interface on the front side of the diamond with regard to the cutting direction, $\tau_{3}$, exceeds the interfacial bond strength and the normal compressive stress at the adjacent interface, $\sigma_{1}$, exceeds the yield strength of the filler. Therefore, the higher average cutting forces and lower average specific cutting forces measured for the specimens with 1 wt. $\%$ binder as well as no observation of failure can be an indication of an increased bond strength as well as an increased yield strength of the filler alloy in comparison with the reference alloy.

The tests with the diamond grains brazed with the filler alloy with a 3 wt.\% binder content showed high $F_{\mathrm{c}} / A_{\mathrm{cu}}$-ratios and only low values for the corresponding cross section area $A_{\text {cu, }}$, which is consistent with the early failure mentioned above. In addition, the cutting force ratio $\mu$ and in particular the normal force $F_{N}$ is significantly smaller in the samples with 3 wt.\% binder. As mentioned above, an insufficient cone formed around the diamond in this case. This leads to a reduced mechanical backing in comparison with the filler alloys with 0.4 and 1 wt. $\%$ binder, respectively. In addition, contact area between the diamond and the filler is reduced, resulting in a high interfacial shear strength $\tau_{3}$.

\section{Conclusions}

This work has shown that the microstructure and thereby the mechanical performance of an $\mathrm{Cu}$-Sn-Ti-based active filler alloy can be influenced by varying the binder content in the brazing paste between 0.4 and 5 wt.\%. For specimens containing $\geq 1$ wt. $\%$ binder, the microstructural analysis has confirmed the existence of nano-sized TiC particles. The amount of $\mathrm{TiC}$ increases with increasing binder content. This is attributed to the reaction of the titanium with the remaining carbon atoms during brazing after the pyrolysis of the $\mathrm{CN}$ binder. The $\mathrm{TiC}$ particles are inhomogeneously distributed in the microstructure. The microhardness and shear tests indicate an increasing strength as a function of the binder contents. The improved mechanical performance is confirmed by the results of the single grain cutting tests in which diamond specimens brazed with a filler containing $1 \mathrm{wt} . \%$ binder showed significantly higher cutting depths and failure forces than the reference samples with 0.4 wt.\% binder. This improvement can be attributed to the formation of the TiC particles, but also to the decrease of the size of the $(\mathrm{Cu}, \mathrm{Sn})_{3} \mathrm{Ti}_{5}$-phase and its more homogeneous distribution in the $(\mathrm{Cu}, \mathrm{Sn})$ matrix. The increased binder content is also accompanied with more liquid brazing paste, leading to a significant reduction of the filler alloy layer thickness after brazing. As a result, samples containing $5 \mathrm{wt} . \%$ of binder showed a poor processability and brazing performance. Even though it does not affect the results of the microhardness and shear tests, it influences the formation of brazing fillet and hinders an effective embedding of the diamonds. This leads to early failure of diamond-steel brazes during the single grain cutting tests.

\section{Acknowledgments}

The authors thank the Swiss National Science Foundation for their support under the grant number 200021-137956/1. In addition, the technical support of KistlerInstrumente AG, Winterthur and Willemin-Macodel SA, Delémont, Switzerland, is gratefully acknowledged.

\section{References}

1. U.E. Klotz, C.L. Liu, F.A. Khalid, and H.R. Elsener, Influence of Brazing Parameters and Alloy Composition on Interface Morphology of Brazed Diamond, Mater. Sci. Eng. A, 2008, 2008(495), p 265-270

2. G. Burkhard, F. Rehsteiner, and B. Schumacher, High Efficiency Abrasive Tool for Honing, CIRP Ann. Manuf. Technol., 2000, 51, p 271-274

3. F.W. Pinto, An Experimental and Numerical Approach to Investigate the Machining Performance of Engineered Grinding Tools, $\mathrm{PhD}$ thesis, ETH Zurich, 2008

4. S. Buhl, C. Leinenbach, R. Spolenak, and K. Wegener, Microstructure, Residual Stresses and Shear Strength of Diamond-Steel Joints Brazed with a Cu-Sn-Based Active Filler Alloy, Int. J. Ref. Met. Hard Mater., 2012, 30, p 16-24

5. S. Buhl, C. Leinenbach, R. Spolenak, and K. Wegener, Failure Mechanism and Cutting Characteristics of Brazed Single Diamond Grains, Int. J. Adv. Manuf. Technol., 2013, 66, p 775-786

6. R.K. Shiue, S.T. Buljan, and T.W. Eagar, Abrasion Resistant Active Braze Alloys for Metal Single Technology, Sci. Technol. Weld. Join., 1997, 2(2), p 71-78

7. Y.Q. Qin and Z.S. Yu, Joining of C/C Composite to TC4 Using SiC Particle Reinforced Brazing Alloy, Mater. Charact, 2010, 61(6), p 635639

8. M.G. Zhu and D.D.L. Chung, Active Brazing Alloy Containing Carbon Fibre For Metal-Ceramic Joining, J. Am. Ceram. Soc., 1994, 77(10), p 2715-2720

9. I. Suedmeyer, M. Rohde, and T. Fuerst, Compound Characterization of Laser Brazed SiC-Steel Joints Using Tungsten Reinforced SnAgTiAlloys, Proc-SPIE7585, Laser-Based Micro- and Nanopackaging and Assembly IV, 2010, 758503

10. H.R. Elsener, U.E. Klotz, F.A. Khalid, D. Piazza, and M. Kiser, The Role of Binder Content on the Microstructure Properties of Cu-Base Active Brazing Filler Metal for Diamond and cBN, Adv. Eng. Mater, 2005, 7(5), p 375-380

11. P. Gasser, U.E. Klotz, F.A. Khalid, and O. Beffort, Site-Specific Specimen Preparation by Focused Ion Beam Milling for Transmission Electron Microscopy of Metal Matrix Composites, Microsc. Microanal., 2004, 10, p 311-316

12. R. Transchel, F. Heini, J. Stirnimann, F. Kuster, C. Leinenbach, and K. Wegener, Influence of the Clearance Angle on the Cutting Efficiency of Blunt, Octahedral-Shaped Diamonds in an Active Filler Alloy, Int. J. Mach. Tools Manuf., 2013, 85, p 9-15

13. R. Transchel, C. Leinenbach, and K. Wegener, Cutting and Ploughing Forces for Small Clearance Angles of Hexa-Octahedron Shaped Diamond Grains, CIRP Annals Manu. Technol., 2014, 63, p 325-328 